\title{
Current Situation and Development Trend of Online Education Technology
}

\author{
Li Wengao \\ Baoshan University, Yunnan, China, 678000
}

Keywords: online education; development tendency; countermeasure

Abstract: In recent years, along with the rapid development of information technology, education teaching mode with the network has become an important way of teaching in higher education institutions. Using the Internet to meet their learning needs has become an important way of learning, and promotes the use of the network to achieve the purpose of teaching in school. So develop high quality online course is an important issue to develop network education at the moment, and how to construct online courses has become a significant problem for every educator to consider. Based on the relevant concepts of the online education, this paper demonstrated the status quo of domestic online education construction and analyzed the existing problems in the process of online education construction.

\section{Introduction}

The rapid development of network technology and the rapid updating of cultural knowledge have put forward higher requirements for human learning and work, as well as new requirements for school curriculum construction. Course problem is the core of education. Course teaching is the basic way to achieve the goal of talent cultivation. It is the inevitable trend of the development of information society to use the Informatization of network technology to drive the Informatization of education. Modern educational technology with network technology as its main feature is being widely used in teaching.

At present, the overall situation of our country's network curriculum construction is not very good, and the learning resources provided cannot meet the learning needs of learners, thus increasing the difficulty of learners in finding relevant information, such network curriculum construction is not conducive to learners' autonomous learning and effective use of resources. Therefore, how to make the network curriculum construction better applied to teaching, to achieve integration with professional or cross-professional curriculum resources, and to promote learners' individualized learning, has become one of the most concerned topics in today's education circles ${ }^{[1]}$.

\section{The Characteristics of Online-Education}

From the definition of the Online-education, we can find that the Online-education mainly contains three aspects. 
- First, the Online-education must cover the basic attributes of teaching methods, teaching activities, teaching contents, educational objectives and other courses.

- Second, the Online-education needs to be carried out based on the network environment and make full use of various network elements.

- Therefore, the Online-education mainly includes the following characteristics:

Firstly, compared with traditional courses, Online-educations have changed in teaching mode, teaching means and learning content, because through the classroom teaching of Online-educations, teachers can constantly absorb new content and new knowledge, so as to ensure that the learning content of Online-educations keeps pace with the times. From figure 1, we can conclude that in this process, teachers change their status from teaching leader to teaching process ${ }^{[2]}$.

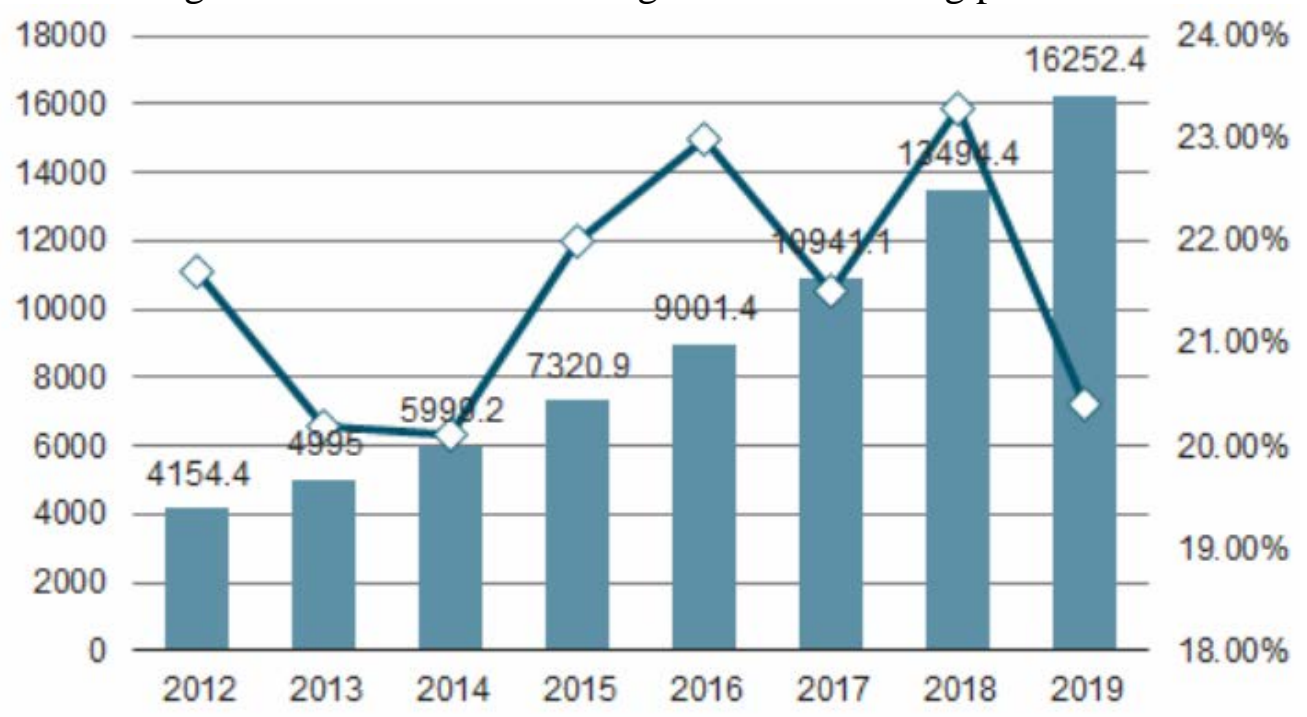

Figure 1 2012-2019 Market Scale of Online Education

Secondly, compared with traditional courses, online courses have more brand-new characteristics in terms of network openness and network organizational characteristics. Learning content is non-linear, that is to say, learning content is mostly in the form of hyperlinks to convey information, so students can choose what they need to learn according to their own knowledge structure, learning background and knowledge proficiency ${ }^{[3]}$.

Thirdly, the learning resources of online courses are shared. The shared resources presented on the Internet are the materials that all students can use for learning and reference. Such a huge amount of information is incomparable with traditional textbooks, courseware, multimedia and television.

\section{Current Situation of Online-education Development and Application}

\subsection{Current Situation of Online-education Development in China}

In recent years, China's colleges and universities continue to carry out the construction of Online-educations, and all colleges and universities have increased their efforts to implement Online-educations, and developed a large number of Online-educations. 


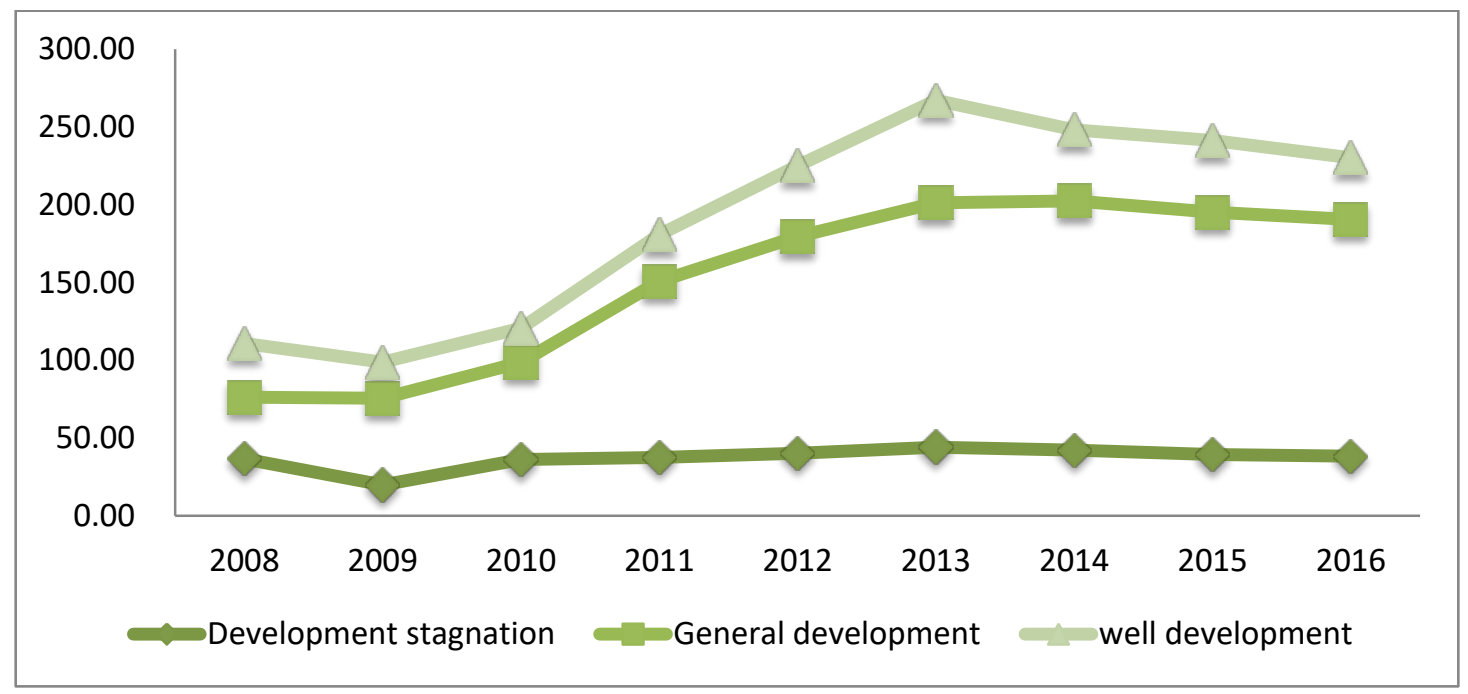

Figure 2 2008-2016 the Scale and Growth Rate Expectation of Network Education Market

From figure 2, the growth rate of 2008-2017 is yearly increased; a large number of Online-educations including junior high school, senior high school, university undergraduate and graduate training have been launched. It is known that at present, more than 200 online courses have been designed, developed and applied by some schools. It can be said that the number of online courses is quite abundant.

From 2003 to now, China has formed three levels of excellent curriculum system: national, provincial and school level, produced a large number of high-quality Online-educations, created and enriched high-quality curriculum resources, and played an important role in promoting the continuous improvement of the quality of higher education teaching in China.

\subsection{Problems in the Development of China's Online Education in the Current Era}

According to statistics, the number of national quality online courses has developed from 151 in 2003 to 873 in 2013. At the same time, more than 6500 provincial quality courses and a large number of school-level quality courses have been promoted by national quality courses. The achievements of the design and development of web-based courses in China are also shown in the following aspects:

- Educational management departments at all levels from the state to the local government and related fields of education Informatization are gradually strengthening the awareness of network curriculum development, and gradually increasing the investment and support for network curriculum development.

- Formed a group of network curriculum development team with thought, theory and technology. A large number of talents have been trained for the development of Online-educations ${ }^{[4]}$.

\subsection{Current Situation of Development and Application of Online-education in China}

The application of web-based courses can be divided into three generations: the first generation provides learners with teaching materials and related materials through web pages, and links with other related educational networks; the second generation requires learners to communicate asynchronously through e-mail, bulletin boards, online exercises and measurements in addition to providing learning materials online; and the third generation is the first generation and the second generation. Use the Fourier function to count this trend: 


$$
f(x)=a_{0}+\sum_{n=1}^{\infty}\left(a_{n} \cos \frac{n \pi x}{L}+b_{n} \sin \frac{n \pi x}{L}\right)
$$

In addition, synchronous two-way communication is required through online chat rooms, teleconferencing and video conferencing systems. At present, the current situation of the application and practice of Online-educations in China is mainly manifested in the following aspects:

- The application of Online-education has been paid more and more attention. The state encourages the development and application of Online-educations through the project of excellent Online-educations.

- Many people have begun to consciously apply Online-educations in their own work practice.

- The application field of Online-education is more and more extensive. Currently, Online-educations have been widely used in higher education, vocational education, adult education, correspondence education, project training and other fields.

- The team participating in the application practice of Online-educations has been growing steadily. Educators at all levels began to use the form of Online-educations to carry out education and teaching in their own work practice.

- Online-education is developing towards systematization. In the application practice of Online-education, people gradually see the limitations of single Online-education, and begin to pay attention to the systematic application of Online-education.

The Online-education application project, represented by the modern distance education project, has received the general attention of the country and various places. The position of the Online-education in the construction of application project resources has been strengthened, and a series of application results have been achieved ${ }^{[5]}$.

\subsection{The Attention and Development Direction of Network Education Technology}

The above client only needs to install a web browser, such as IE/NS, so it can be low on the machine itself based on any operating platform that supports Browser. The web server is used to manage the information flow between the client and the application server. The application server responds to the request sent by the WEB server, activates the corresponding query task, and utilizes the interface technology to access the data warehouse, such as ODBC and JDBC, and mainly includes the following aspects:

$\checkmark$ Selection of data

- Assimilation of knowledge

$\checkmark$ Data conversion

Data mining

- Analysis of results

Data pre-processing

Various popular servers, such as IIS, APACHE, etc., can be used by the web server to accept client HTTP requests, and generate dynamic HTML response requests by using static HTML pages or calling the application server. After verification of legality and the like, a request is made to the application server according to the content of the WEB page, and an application such as jsp or asp may be installed on the WEB server, so that information can be exchanged with the application server.

\section{Conclusions}

On the whole, the practice and application of web-based courses in China has not been on the right track, and the application of web-based courses is far from meeting the requirements of the 
development of educational Informatization. The effect of web-based course teaching is not very ideal, and to some extent, there is the phenomenon of applying web-based course for web-based course. All these require us to further understand the Online-education, strengthen the application practice of the Online-education, strengthen the research work on the application practice of the Online-education, and explore the new theory, new experience and new ways of the practice application of the Online-education.

\section{References}

[1] Chen Z L, Chen J Y, Liu H, et al. Present status and development trends of underground space in Chinese cities: Evaluation and analysis[J]. Tunnelling \& Underground Space Technology, 2018, 71:253-270.

[2] RaedA Azhar, AhmedA Mobaraki, HattanM Badr, et al. Current status of robot-assisted urologic surgery in Saudi Arabia: Trends and opinions from an Internet-based survey[J]. Urology Annals, 2018, 10(3):263-269.

[3] Hu M, Li Y B, Li X, et al. The Roll-Forming Process Analysis of the Situation and Development Trend[J]. Key Engineering Materials, 2018, 764:201-209.

[4] Jiang F, Yuanfeng L I, Chen S. Current Situation and Prospects of Welding Arc Monitoring Technology[J]. Journal of Mechanical Engineering, 2018, 54(2):16.

[5] Fernández I, Márquez M D. Educational development units in Spain: current status and emerging trends[J]. International Journal for Academic Development, 2017, 22(4):1-17. 